dures should be standardized and professional.

3. Untenured women faculty should be protected from being overburdened by service assignments.

4. Department chairs should prevent bias from entering the review process through the interpretation of vitae, the reading of letters of recommendation, the treatment of coauthored research, the devaluing of women reviewers, and the devaluation of women and politics research.

5. Universities and departments should adopt family leave policies.

\section{Faculty Development}

1. The elimination of a "chilly climate" for women benefits all members of a department. Accordingly, department chairs can improve the working environment for women - faculty, students, and staff-by educating their faculty about the nature and consequences of sexual harassment and gender insensitivity.

2. Gender inequities in the classroom should be reduced by encouraging faculty to develop courses that are gender-inclusive in their content, and by sensitizing faculty to the subtle ways in which classroom behavior can create a "chilly climate" for women students.

3. Departments should take a number of steps to increase the likelihood that women will succeed at research.
a. The tendency to devalue women as political scientists as well as "women and politics" as political science can be reduced by expos- ing the entire faculty to the research of women.
b. Mentoring should be encouraged to further the research of women faculty.
c. Junior faculty should have annual

conferences with the chair to discuss their concerns, while the chair is able to express the department's concerns.

\section{Graduate Students}

1. Political scientists should actively encourage women to attend graduate school.

2. Financial aid decisions should be made in a gender-neutral fashion.

3. All graduate students should receive professional mentoring. In addition, where appropriate, women graduate students should be offered additional personal mentoring to help them overcome the barriers created by long-standing gender bias in society and the educational process.

4. All students and faculty should be informed about their institution's sexual harassment policy.

I have supervised graduates of some of the most prestigious policy study programs in this country, and while most of them are prepared for the nitty-gritty of public service (e.g., fiscal policy, procurement procedures), they are relatively ignorant when it comes to the conceptual frameworks common to political science. The result is that we are producing a generation of worker beeswhich is helpful in some respects. The problem, however, is that if they cannot conceptualize problems, then the policy-makers for whom they work, and who have neither the time nor the interest in such schemes, will not see the issues they must resolve from a broad perspective. Only a good grounding in a field such as political science-whether while a student or at the mid-career point when one is sent back to the university for graduate training-will teach practitioners the desired abstract thinking ability. 
The major obstacle to imparting the abstract conceptualizing ability so needed by practitioners is that the vast majority of what passes for IR and comparative theory appears to such individuals to be so abstract or distorting of the real situation that it is useless. This raises a key question. Does the political scientist have an obligation or an interest in producing policy-relevant conceptual approaches? In fact, while political scientists are more than prepared to argue in favor of non-policy-oriented analyses in their academic work, the vast majority of the ones $I$ have met over the years need little prompting to offer prescriptive policy suggestions-often tying such prescriptions to their own work. "My work on country $X$ shows that we should be doing Y." Such individuals cannot have it both ways. If they opt to stay out of the policy process, fine. But if they hope to influence it, then they must construct their analyses so that policy makers will find them useful.

\section{Reasons for the Divergence}

Theory Is a Bad Word. Previously, theoretical work in areas associated with foreign policy changed very little over the years. Twenty or 25 years ago, a knowledge of Hans Morgenthau or Reinhold Niebuhr along with a Ph.D. and a number of publications were sufficient to qualify anyone as an academic specialist in foreign affairs. This situation has changed dramatically. There has been an explosion in theory. At present it is impossible to function in fields such as comparative politics or IR without an in-depth knowledge of major theoretical approaches such as developmental theory (in spite of its many problems), political economy or IPE, dependency theory, the bureaucratic-authoritarian model, game theory, corporatism, etc., in addition to more traditional approaches such as the schools of realism and liberalism (or as some call them now, the neo-realist and neo-liberal approaches).

At first glance, it is not surprising that practitioners are hostile to many, if not most, of the theoretical frameworks currently being employed in the discipline. The vast majority of them either attended university before these newer approaches became standard in most political science courses, avoided courses using such approaches, or have not kept up with this dynamic and changing field. In addition, they are often so caught up in dealing with timeurgent, day-to-day problems that they have little opportunity to reflect on the conceptual relevance of the issues under consideration.

Some political scientists-and practitioners as well-claim that the wall separating the two sides cannot be penetrated. Practitioners will never accept the importance or usefulness of conceptual frameworks. I disagree. When I began teaching at the National War College, I was warned not to mention the word "theory." "These are people who disdain theory; they have operated in the real world and are very suspicious of anything even remotely resembling theory. For them it is a bad word."

In fact, I found the opposite to be the case. Throughout my courses, I made it clear to classes of colonels, captains, and equivalent civil servants that we were going to use a variety of conceptual/theoretical approaches. In my East European course, for example, I made political culture the primary framework around which the course centered. We spent one whole session on the concept, its origin, and its strengths and weaknesses. Looking at the communist period, all of the countries of the region were treated through the prism of political culture (both elite and mass), and when dealing with the post-communist era, we again turned to political culture, asking the question, what must be done to build an acceptable/democratic political culture?

The reaction-at first hesitant, in a few cases hostile-after the first couple of weeks was enthusiastically supportive. Once these practitioners could see a practical use for a concept like political culture (any other theoretical framework could have been used; I happen to like working with political culture), they found it very helpful as a way of organizing data and providing a coherent framework for analysis. All of a sudden, both Hoxha's irrational efforts to radically change the attitudes and behaviors of Albanians and the magnitude of the problems facing the new democratically elected leadership became comprehensible to this group of practitioners. I later discovered that a number of them were appropriating the concept of political culture for their own analyses of problems such as political reliabilitywhich is critical for problems such as calculating the military balance.

Given this-at least potentialreceptivity to theoretical constructs, why is the gap between practitioners and political scientists widening? Why do practitioners increasingly believe that the majority of what is coming out of comparative politics and IR is not applicable when it comes to dealing with real problems? There are a number of reasons that help explain this unfortunate situation.

Acultural Attitudes. In many cases, one meets political scientists who have minimal respect for factors such as history, language, or area knowledge. As one leading individual in the field put it to me, "We have gone beyond the need for this type of information." There appears to be a belief among such individuals that the power of their theoretical frameworks is so strong that they can dispense with such idiosyncratic knowledge. "Individual cases may vary, but we are looking for nomothetic variables, and for that reason we do not need to know languages or have an intimate familiarity with the history, politics, or culture of a particular country," is the way one leading theoretician put it to me several months ago.

To a certain degree, this attitude can be explained by the increasing linguistic and cultural illiteracy on the part of political scientists: since we don't know the languages or the cultural background of the countries we study, let us find a conceptual framework that will do our work for us. Nevertheless, it flies in the face of what specialists in foreign affairs consider critical. "How," one of my Foreign Service colleagues once complained to me, "can anyone hope to say anything meaningful about a non-American political system if he or she does not have at least minimal knowledge of the country's language, 
culture, and history?" When I pointed out that many in political science are attempting to take information from a number of cases in order to permit generalizations, the response was, "superficial knowledge gives superficial generalizations."

\section{$A$ Closed Profession? To a large} degree, political science has become a closed profession. Political scientists - and many other fields as welltend to be suspicious of those without a classic academic background. One often encounters a fear-indeed a very strong one-of practitioners with practical experience. Some of this dislike for foreign affairs practitioners is no doubt justified. In many cases practitioners are accepted into political science departments and do not carry their weight. The stories of ex-FSOs who have retired in place, specialized in telling anecdotes, or spent a year as a diplomat-inresidence doing nothing are legion. Such individuals often give the impression of being so burned out by their years in the State Department and so turned off by the current direction that political science is taking (conceptually) that they are more of a problem than a help.

Admitting that practitioners (and FSOs in particular) are often their own worst enemies, there is still a problem with the political scientist who is easily threatened by a practitioner who confronts the former's theoretical analysis with the words, "that is not the way it happened, I know, I was part of the decisionmaking process." I can still remember a very antagonistic and hostile reaction on the part of a political scientist, specializing in the U.S. national security decision-making process, when a Foreign Service colleague of mine said that his theoretical framework concerning the Pentagon's public position vis-à-vis the Soviet threat was wrong. Everyone in the Pentagon knew that its public position had nothing to do with the USSR per se. Rather it reflected its real concern-the budgetary process. The political scientist was furious. In fact, this practitioner had spent time both on the Hill and in the Pentagon. He had seen the policy process first hand and knew that reality is not always what a theoretical framework suggests it is or should be.
The reaction of many political science departments to this situation is to build a wall between themselves and those with practical experience, thereby avoiding conflicting opinions and approaches. Such a situation is made worse by the existence of what amounts to a "liberum veto" in many departments-one or two opposed, especially if they are on the hiring committee, and the practitioner does not stand a chance of getting in. Furthermore, bringing in individuals with a practical background usually means that they are older and therefore will probably be hired at the associate or full levelsomething that many junior faculty tend to oppose. The current difficult economic situation faced by this country only serves to heighten the fears of junior faculty members concerning tenure and promotion. While the exclusion of individuals with practical experience may help create a comfortable feeling on the part of some departments-we all think alike, so therefore we must be right -it tends to undermine the value political science departments have in the eyes of practitioners. Indeed, contrary to what many political scientists think, practitioners are very suspicious of "group think." They like to encounter a variety of different points of view; after all they work in a world where they are constantly confronted with the needpublicly at least-to adapt to an agency or department or government position.

\section{The Ideological Imperative. One of} the biggest surprises on the part of many practitioners in dealing with political scientists who specialize in foreign policy affairs is how little the latter seem to understand about how foreign policy is formulated and implemented in the "real" world. This situation is made worse by the tendency on the part of some to see bureaucratic politics in Washington through the eyes of a particular ideology. All military officers are right wing, or all Foreign Service Officers are conservative, are phrases I have heard too often from some of my political science colleagues. In fact, practitioners-including military officers-tend to be as diverse in terms of their political views as is the case with other groups in our society.
Some military officers are right wing and some Foreign Service Officers are conservative. On the other hand, I have met many military officers who are anything but right wing and many FSOs who are very liberal in their approach to foreign policy. The fact is that career bureaucrats are a diverse group of people. Stereotyping them on the basis of their occupation is just as wrong as stereotyping individuals on the basis of their race, religion, or gender.

Furthermore, while career bureaucrats play an important role in framing and structuring foreign policy issues in Washington, they do not make the major decisions. In 25 years in the Foreign Service-operating on occasion at very senior levels -I did not see a single instance in which a major change in policy was instituted by a career bureaucrat. Such changes almost always occurred as a result of actions by political appointees or pressure from the Hill, a domestic pressure group, or the White House. If anything, most practitioners with whom I have worked tend to ameliorate the more radical policy changes favored by political appointees. This helps explain, for example, why the Foreign Service, in particular, was so disliked by the Reagan Administration. Political appointees constantly ran into FSOs, who worked assiducusly to deradicalize some of their more right-wing proposals.

Despite the reality of Washington bureaucratic politics, I saw some of my Foreign Service colleagues, who worked on Central America, bitterly attacked by political scientists, who claimed that their hands were "dripping in blood." In fact, I know from first-hand experience that these individuals strongly opposed U.S. policy in the region and had written dissenting memoranda arguing that our policy was wrong on both moral and practical grounds. Career civil servants, including the military and the Foreign Service, have two options once a policy decision is made. Carry it out-but dissent privately if you want-or resign your commission, and in the case of the Reagan Administration, leave policy in the hands of the true believers. Criticizing these individuals for their involvement with Central America makes about as much sense as giving 
me credit for what has happened in East Germany, Eastern Europe, and the former Soviet Union-a region to which I devoted my Foreign Service career. In making such blanket accusations, political scientists often alienate themselves from individuals who are most sympathetic to their criticisms of U.S. foreign policy.

Speaking Ex Cathedra. From the standpoint of a practitioner, there are three general approaches to theorizing about $\mathrm{IR}$ and comparative politics. ${ }^{2}$ To begin with, there is what I will call the inductive approach, best exemplified by the work of $J$. David Singer and his students in the Correlates of War Project. From the perspective of a practitioner, such work has little relevance to dealing with "real" problems. Indeed, the conclusions reached by members of this group sometimes sound silly to the practitioner. For example, suggestions that as a consequence of this project we now know that the formation of alliances is associated with wars, produce only smiles on the faces of practitioners. ${ }^{3}$ Obviously, alliances and wars sometimes, perhaps even frequently, go together. But does that mean that the formation of NATO or the now defunct Warsaw Pact was likely to lead to war? History has supplied a negative answer to this question. In fact, an argument can be made that NATO helped keep the peace. From the practitioner's standpoint, suggestions by Singer that "after literally centuries of inconclusive theorizing and philosophizing on the causes of war, real progress in our knowledge is beginning to be made," seem somewhat exaggerated (Singer 1981).

The second theoretical approach is what I will call the deductive or a grand theory approach. Under this rubric, the analyst uses a broad deductive approach (e.g., balance of power) to order data-i.e., to give them coherence. The problem with such analyses from the perspective of a practitioner is that the theoretical framework sometimes controls the data to such a degree that conclusions seem forced by the framework. Take Mearsheimer's proposal to give the Germans nuclear weapons. When one gets to the heart of his argument, it is that the balance of power theory makes it imperative that there be an equal balance of military forces in Europe. By giving the Germans nuclear weapons, he argues, they will feel secure and the chances for long-term stability in the region will increase. From the point of view of a practitioner, this represents a theory in search of reality. Most with whom I have spoken consider it a prescription of what not to do (Mearsheimer 1990).

A third, and from the perspective of a practitioner, far more useful approach is what Robert Merton many years ago called mid-range theory. Under this approach, the primary focus of the analyst is on developing testable hypotheses on the relationship between two policy relevant variables. The problem from a theoretical standpoint is that it is difficult to generalize beyond the single case under study, although this approach does offer the distant promise that as such relationships are tested and proven to exist, they can be interrelated with other variables and a theoretical framework can be gradually constructed. There are many such analyses, such as the classic study by Alexander George and Richard Smoke on the interrelationship between external and internal variables in formulating and implementing U.S. foreign policy. A more recent example is Jack Snyder's study of the relationship between such variables in Germany, Japan, Great Britain, the USSR, and the United States. The fact is that within the U.S. government, the majority of action takes place on the micro, not the macro level, and mid-range theory has the advantage of producing conclusions that tend to be immediately relevant to the policymaking process. The downside is that this type of theory building is a long, slow, and potentially unsuccessful process (George and Smoke 1974; Snyder 1992).

\section{An Alternative Approach}

Assuming that I am correct in believing that the majority of political scientists, specializing in foreign affairs, want to do work that both contributes to theory building and is helpful to policy makers, a number of steps can be taken to begin to open a dialogue.

- When writing articles or books that are not meant to be policy relevant, say so. There is nothing wrong with such works.

- Become more open to interaction with practitioners whether it is in the form of conferences, guest speakers, or as colleagues in a political science department. If one accepts criticism as a useful vehicle for building knowledge, political scientists should welcome the comments -even if sometimes irrelevant or wrong-of those with practical experience. Political scientists should not be too insecure to accept criticism. The fact is that all work could be better, and it may be that the practitioner's criticism will not be easy to take. If, on the other hand, it leads to improved conceptualization, this will be a step forward.

- Policy oriented schools, which attempt to train individuals to perform specific tasks for the Washington policy process, need to be reformed. Based on my experience, the conceptualizing ability of graduates of some of the best known schools of this type is very shaky. In fact, much of their analytical training turns out to be of minimal utility. As a supervisor-and I think I am speaking for many of my former colleagues around Washington-I would rather have a young officer trained to conceptualize problems, than I would someone, however expert in the budgetary process or in procurement or planning, who has little idea of "what it all means conceptually."

- In writing conceptual/theoretical pieces aimed at policy makers, look upon theory as a heuristic device. This is especially true of deductive or inductive analyses. Both can be very useful in helping practitioners understand the domestic and international variables that affect the formulation and implementation of foreign policy. But to be credible they must be used with caution. Besides, given the present state of theory building in political science, it is silly to argue that we have a theory capable of explaining human behavior. At best we have partial theories. We are all stumbling in the dark. If nothing else, such studies can help sensitize practitioners to variables that can 
and will have a major impact on the policy process. For example, if it were in my power, I would make it a requirement for all practitioners to read Jervis's classic Perceptions and Misperceptions in International Relations, not because the framework will help them solve the problems they are dealing with, but because it will sensitize them to the affect their own actions will have on the other sideespecially when it involves another political culture (Jervis 1976).

In an ideal world, practitioners could be expected to meet political scientists half way in opening up a dialogue on how to make theory more relevant and useful in the policy process. The real world, however, is far from ideal. Based on my own experience, I think the sense of alienation from political science felt by most practitioners with whom I have been associated is so strong that many, if not most of them, have given up on our discipline. Recently, for example, I was talking to a number of practitioners who have been given the task of coming up with a U.S. government approach for dealing with post-communist Eastern Europe. I asked if they had consulted the political science community. The answer was-to me personally-discouraging. "All we get is babble about the process of democratization. None of them seem to know anything substantive about the region. They are useless." While this is clearly an exaggeration, it exemplifies the mind-set on the part of many practitioners. ${ }^{4}$ What is worse, many of these people play an important role in funding research engaged in by political scientists; not a positive sign for our discipline at a time of fiscal stringency.
Foreign affairs analysis by political scientists is at a crossroad. On the one hand, it can continue to follow the "theory for the sake of theory" route it has for the past 10 years in the hope that at some point in time it will become policy relevant. In the meantime, it will become increasingly less and less useful to policy makers and the practitioners who back them up. The other path-an admittedly rough and difficult one-will require a good dose of humility on the part of political scientists, but its short and mid-term pay off in terms of its impact on the policy process is likely to be considerable. Besides, in the process we might come up with the elusive theoretical framework we have been seeking for the past $\mathbf{3 5}$ odd years.

\section{Notes}

*The author would like to thank his colleagues at the Wilson Center for their helpful, critical comments in the preparation of this essay. An earlier version of this article appeared in the Foreign Service Journal, November 1991.

1. By practitioners I mean those career bureaucrats, whether Foreign Service, Civil Service or military, who generally frame problems, do the staff work necessary to obtain inter-agency approval and executive level decisions, and in the process exert a tremendous influence on the policy process. Policy maker generally refers to political appointees, who tend to spend three or four years in the government and then return to their regular civilian occupation.

2. This categorization is subjective on my part, although it is based on discussions with a number of practitioners, and I believe most would agree "more or less" with this breakdown.

3. See, for example, Vasquez 1987. I am using Vasquez's essay only for purposes of illustration. It is in fact a very useful introduction to the work done by Singer and his students.
4. I subsequently learned that my interlocutors were referring to the ideas expressed in Huntington's new book (1991). I personally found Huntington's approach useful in my own work; a view obviously not shared by some of my practitioner-colleagues.

\section{References}

George, Alexander, and Richard Smoke. 1974. Deterrence in U.S. Foreign Policy. New York: Columbia University Press.

Huntington, Samuel P. 1991. The Third Wave; Democratization in the Late Twentieth Century. Norman: University of Oklahoma Press.

Jervis, Robert. 1976. Perception and Misperception in International Relations. Princeton: Princeton University Press.

Mearsheimer, John J. 1990. "Back to the Future: Instability in Europe After the Cold War." International Security 15: 5-56.

Singer, J. David. 1981. "Accounting for International War: The State of the Discipline." Journal of Peace Research 18: $1-18$.

Snyder, Jack. 1992. Myths of Empire; Domestic Politics and International Ambitions. Ithaca: Cornell University Press.

Vasquez, John A. 1987. "The Steps to War: Toward a Scientific Explanation of Correlates of War Findings." World Politics 40: 108-45.

\section{About the Author}

After 25 years in the Foreign Service, Dale Herspring retired to become a professor of international security affairs at the National War College. He has also taught at Georgetown University for the last 11 years as well as at Columbia and the University of Maryland. $\mathrm{He}$ is the author/editor of five books and more than forty articles on Russian, Soviet, and East European affairs. His most recent book, published by Princeton, is entitled, The Soviet High Command, 1967 . 1989; Personalities and Politics. He spent last year as a fellow at the Woodrow Wilson Center for International Scholars writing a book, also to be published by Princeton, to be entitled, Military Reform in the Former Soviet Union; A Study in Political Culture. 